\title{
Genotype versus phenotype in cardiology: just a new coat of paint?
}

\section{"Genetic testing in cardiology comes with great promise, even for individualized medicine for better patient care."}

\section{KEYWORDS: ANP $\approx$ BNP $\approx$ cardiovascular $\approx$ genetic $\approx$ heart failure $\approx$ natriuretic peptide}

DNA makes RNA makes protein. This pregraduate dogma has been with us since the discovery of RNA (first) and DNA (later), and still affects our way of understanding genetic testing in clinical practice. Today, genetic testing has become an integral part of hospital laboratories, where testing ranges from the evaluation of risk in general and selected cohort studies to pinpointing specific molecular defects in disease. As such, genetic testing in cardiology has been available for some time [1], where, for instance, familial hypercholesterolemia can be diagnosed. High-throughput technology has taken the testing further - from former laborious and time-consuming analyses to methods that can meet the clinical demand for results within a meaningful timespan. In this editorial, we highlight a few of the translational challenges in genetic cardiology, using the natriuretic peptide system as a model.

Cardiac natriuretic peptides have been known for 30 years [2]. The coding genes for ANP, BNP and their receptors were identified during the 1980s. Plasma measurement of the peptide products rapidly gained cardiological interest as increased plasma concentrations were noted in heart failure [3]. Today, plasma measurement of the peptide products is an integral part of assessing cardiac dysfunction, where normal concentrations can exclude left ventricular dysfunction in the untreated patient $[4,5]$. One early study reported that plasma concentrations were also associated with heredity in apparently healthy individuals [6], which in some ways preceded the later genetic interest in the hormonal system. Genetic studies in man focused first on the receptor $N P R-A$ as the gene is large and prone to variation [7]. Given the blood pressure-lowering effects of the hormone system, genetic testing looked for an association with a phenotype of hypertension (loss of function). Also, a cardiac endoprotease (corin) presumed responsible for hormonal maturation has been examined with a focus on hypertension [8]. Taken together, the studies have demonstrated a biological link between genetic disturbance in the hormone system and hypertension, but the clinical interpretation and possible treatment action from the studies are limited. Hypertension as a phenotype has documented possibilities for intervention (weight loss, physical training and medical therapy); therefore, the studies have not had consequences for patient treatment.

Other studies investigated associations between genetic variation in the natriuretic peptide system, and the risk of diabetes and obesity $[9,10]$. Again, an association has been suggested, but the clinical impact seems to be nonexistent. Obesity is best dealt with by weight loss, and diabetes has its own effective treatments. A more recent study used a different approach involving a family with lone atrial fibrillation [11]. This study showed that a mutation in the $A N P$ gene gives rise to a mutant peptide with prolonged elimination in circulation; thus, this was most likely a 'gain-of-function' mutation [12]. While this information is valuable from a biological (and pharmacological) point of view, the net effect in clinical cardiology is again limited.

Another way of testing the impact of genotype on phenotype is by examining genetic alterations in experimental animals. From this method it has become clear that the natriuretic peptide system is tightly related to circulatory volume regulation and resultant blood pressure [13]. However, serious caution should be exercised with the natriuretic peptide mouse models. Knocking out one particular gene may seem like removing one part of a car engine and then proceeding to look for functional defects when the car has been parked. Mother nature, however, has her own ways of

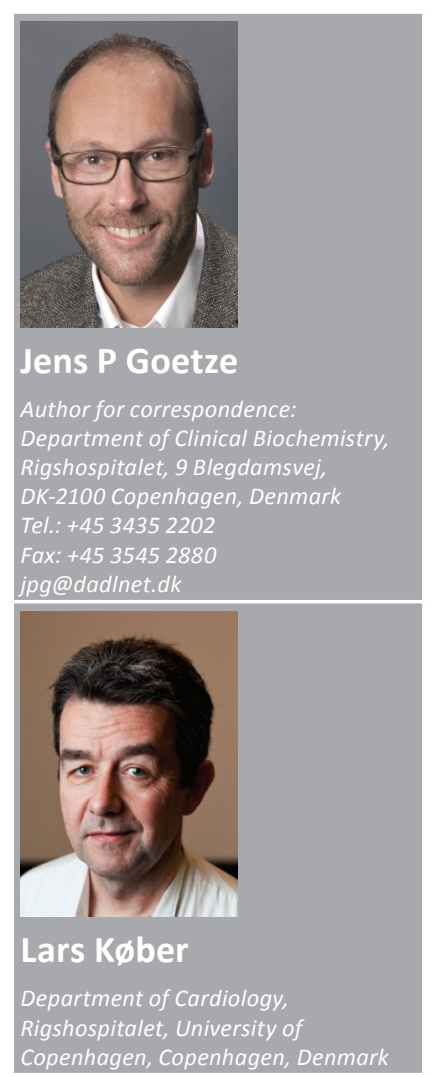

Future
Medicine 
finding compensatory ways of survival. Also, hormonal systems are often expressed together with related genes (gene superfamily) that may compensate for the loss. Thus, interpretation from cardiovascular mouse models is as much a discipline of studying one gene as it is a complex example of how biology can find its way around gross defects. The last approach to testing the effect of a genotype on phenotype can be performed using human epidemiology. This has also been tried and resulted in some biological suggestions and associations but with no direct impact on clinical practice.

So, is genetic testing just a new coat of paint in the laboratory arsenal of possible measurements? We believe so, to some degree. The relationship between cause and consequence needs much more scrutiny in the clinical field of investigation of testable parameters. With genetic tests even available over the internet, patients are at an alarming risk of obtaining information without consequence, which we would to classify as misinformation.

\section{"...interpretation from cardiovascular mouse models is as much a discipline of studying one gene as it is a complex example of how biology can find its way around gross defects."}

Take the following theoretical example: a subject may purchase a genetic test package via the internet and receive the results in an e-mail. The data show a change in gene X, for which there is no functional protein test. The laboratory report notes that the polymorphism has been associated with a fivefold increase in the risk of sudden death. The subject may contact his/her doctor with this information asking for advice. There is a possible intervention, but it comes with both risk and concern; the doctor therefore advises that there is no immediate intervention and that the isolated risk factor should be interpreted in the context of many other risk factors in life. However, the subject may still be concerned with the 'ticking bomb' within both the subject and his/her relatives, with the psychological implications of this affecting the subject's day-to-day and family life [14]. The genetic test itself only set the subject back US\$99.

The situation is very different in a patient or a relative with a specific phenotype. In cardiology, many disorders are caused by genetic variants with variable disease expression. They include a heterogeneous group of cardiomyopathies (hypertrophic, dilated, restrictive, arrhythmogenic and left ventricular noncompaction) as well as ion channel diseases (long QT syndrome, short QT syndrome, Brugada syndrome, catecholaminergic polymorphic ventricular tachycardia, familial atrial fibrillation and inherited conduction disorders) as well as arterial diseases (Marfan syndrome, Ehlers-Danlos syndrome, Loeys-Dietz syndrome and familial thoracic aortic aneurysms). These syndromes are considered to be monogenic, but the reductive thinking that one genetic variation equals one disease is too simplistic. Affected patients may carry more than one mutation that may affect the overall clinical expression. However, if a genetic diagnosis can be made in the proband, this may be very helpful in family counseling. The European Society of Cardiology has made a position paper in order to assist with defining the role of genetic testing and counseling [15]. At present, genetic testing should be restricted to selected patients or for certain types of cardiomyopathies after detailed clinical and family assessments. These include a phenotype of arrhythmogenic cardiomyopathy or presence of atypical phenotypic features, when a correct diagnosis can result in the recommendation of a specific therapy (i.e., liver transplantation in transthyretinrelated amyloidosis or prophylactic defibrillator implantation in dilated cardiomyopathy caused by a lamin A/C gene mutation).

Genetic testing in cardiology comes with great promise, even for individualized medicine for better patient care. However, the need for experienced clinicians is higher than ever as the flow of information and misinformation in itself can harbor disease. Today, genetic testing without reason or rationale for intervention should be approached with skepticism, as it may harm and not heal. The ancient Greek doctor and philosopher Hippocrates emphasized on this aspect 2500 years ago (to help, or at least, to do no harm), and the message is still prudent in the era of genetic medicine.

Financial \& competing interests disclosure The authors have no relevant affiliations or financial involvement with any organization or entity with a financial interest in or financial conflict with the subject matter or materials discussed in the manuscript. This includes employment, consultancies, honoraria, stock ownership or options, expert testimony, grants or patents received or pending, or royalties.

No writing assistance was utilized in the production of this manuscript. 


\section{References}

1 Brown MS, Goldstein JL. Familial hypercholesterolemia: genetic, biochemical and pathophysiologic considerations. $A d v$. Intern. Med. 20, 273-296 (1975).

2 de Bold AJ. Thirty years of research on atrial natriuretic factor: historical background and emerging concepts. Can. J. Physiol. Pharmacol. 89, 527-531 (2011).

3 Burnett JC Jr, Kao PC, Hu DC et al. Atrial natriuretic peptide elevation in congestive heart failure in the human. Science 231, 1145-1147 (1986).

4 Goetze JP. B-type natriuretic peptide: from posttranslational processing to clinical measurement. Clin. Chem. 58, 83-91 (2012).

5 Piran S, Liu P, Morales A, Hershberger RE. Where genome meets phenome: rationale for integrating genetic and protein biomarkers in the diagnosis and management of dilated cardiomyopathy and heart failure. J. Am. Coll. Cardiol. 60, 283-289 (2012).

6 Wang TJ, Larson MG, Levy D et al. Heritability and genetic linkage of plasma natriuretic peptide levels. Circulation 108, 13-16 (2003).

7 Pandey KN. The functional genomics of guanylylcyclase/natriuretic peptide receptor-A: perspectives and paradigms. FEBS J. 278, 1792-1807 (2011).

8 Dries DL, Victor RG, Rame JE et al. Corin gene minor allele defined by 2 missense mutations is common in blacks and associated with high blood pressure and hypertension. Circulation 112, 2403-2410 (2005).

9 Meirhaeghe A, Sandhu MS, McCarthy MI et al. Association between the T-381C polymorphism of the brain natriuretic peptide gene and risk of Type 2 diabetes in human populations. Hum. Mol. Genet. 16, 1343-1350 (2007).

10 Pfister R, Sharp S, Luben R et al. Mendelian randomization study of B-type natriuretic peptide and Type 2 diabetes: evidence of causal association from population studies. PLoS Med. 8(10), e1001112 (2011).

11 Hodgson-Zingman DM, Karst ML, Zingman LV et al. Atrial natriuretic peptide frameshift mutation in familial atrial fibrillation. N. Engl. J. Med. 359, 158-165 (2008).

12 McKie PM, Cataliotti A, Huntley BK, Martin FL, Olson TM, Burnett JC Jr. A human atrial natriuretic peptide gene mutation reveals a novel peptide with enhanced blood pressurelowering, renal-enhancing, and aldosteronesuppressing actions. J. Am. Coll. Cardiol. 54, 1024-1032 (2009).

13 Gardner DG, Chen S, Glenn DJ, Grigsby CL. Molecular biology of the natriuretic peptide system: implications for physiology and hypertension. Hypertension 49, 419-426 (2007).

14 Bergen M, Goetze JP. On the nature of depression: cardiovascular light for a shady condition. Cardiovasc. Endocrinol. 2, 38-39 (2013).

15 Charron P, Arad M, Arbustini E et al.; European Society of Cardiology Working Group on Myocardial and Pericardial Diseases. Genetic counselling and testing in cardiomyopathies: a position statement of the European Society of Cardiology Working Group on Myocardial and Pericardial Diseases. Eur. Heart J. 31, 2715-2726 (2010). 